\title{
Assessing sulfur isotope variability in the Icelandic mantle: evidence from subglacial glasses and melt inclusions
}

S.A. HALLDÓRSSON ${ }^{1 *}$, E. RANTA ${ }^{1}$, J.GUNNARSSON

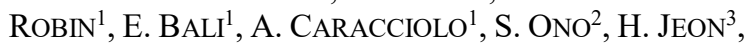
M.J. WHITEHOUSE ${ }^{3}$, M.E. HARTLEY ${ }^{4}$, J.K. DHALIWAL ${ }^{5}$, S. MATTHEWS ${ }^{6}$, A. STEFÁNSSON ${ }^{1}$

${ }^{1}$ Nordvulk, IES, University of Iceland, Reykjavík, Iceland

(*correspondence saemiah@hi.is)

${ }^{2}$ MIT, Boston, MA, USA

${ }^{3}$ NORDSIMS, SMNH, Stockholm, Sweden

${ }^{4}$ University of Manchester, Manchester, UK

${ }^{5}$ University of California, Santa Cruz, CA, USA

${ }^{6}$ Johns Hopkins University, Baltimore, MD, USA

A considerable range in $\delta^{34} \mathrm{~S}$ values has been reported for Icelandic lavas [1], but potential flaws in older sulfur extraction methods [2] and the degassed nature of the analyzed lavas question the reliability of this dataset. We have therefore undertaken a systematic study following the newly proposed HF-extraction method [2] to evaluate the sulfur isotopic characteristics of Icelandic lavas. We focus on a suite of subglacial basalts $(\mathrm{n}=59)$ and a set of previously studied silicate melt inclusion from central Iceland $(n=29)$ $[3,4]$. Select samples from subaerially-erupted lavas $(n=15)$ exhibiting evidence for degassing have also been included. A new set of SIMS standards have been prepared following [2] for the purpose of obtaining high-quality $\delta^{34} \mathrm{~S}$ values from silicate glasses trapped in crystals.

Relatively high sulfur contents $(>500 \mathrm{ppm})$ and S/Dy comparable to, but generally higher than, estimates for depleted MORB mantle (DMM: 150-310), are consistent with the relatively un-degassed nature of most samples analyzed. The entire sample suite records a large range in $\delta^{34} \mathrm{~S}$ values (3.8 to $+3.8 \%$ oy SIMS and IRMS). Degassed samples display the highest $\delta^{34} \mathrm{~S}$ values whereas a more restricted range $(-2.5$ to $+0.5 \%$ ) is observed for most samples containing $>500$ ppm. For this group, subglacial glass samples and silicate melt inclusions reveal overlapping $\delta^{34} \mathrm{~S}$ values, averaging at $1.2 \%$ o $( \pm 0.6 ; 1 \sigma, \mathrm{n}=92)$, which is identical to estimates for DMM [2]. A group of high-MgO glasses record a large range in $\delta^{34} \mathrm{~S}$ values (from -3.8 to $+0.5 \%$ ) at $\sim 1100 \mathrm{ppm}[\mathrm{S}]$, exceeding greatly the range evident in another group of high$\mathrm{MgO}$ glasses with $\leq 800 \mathrm{ppm}[\mathrm{S}]$. This $10 \mathrm{w}-\delta^{34} \mathrm{~S}$ group also reveals $\mathrm{S} / \mathrm{Dy}$ as high as 615 , suggesting primary (mantlederived) controls on $\delta^{34} \mathrm{~S}$ values in Icelandic basalts.

[1] Torssander, P. (1989), CMP 102(1), 18-23. [2] Labidi, J., et al. (2012). CG, 334, 189-198. [3] Caracciolo et al. (2020) Lithos, 352-353, [4] Bali et al. (2018) CMP, 173:9. 